\title{
O processo de consolidação e desenvolvimento da unidade pediátrica de um hospital filantrópico sob o olhar das tipologias de adaptação estratégica
}

\author{
Juliana da Fonseca Capssa Lima Sausen* \\ Jorge Oneide Sausen** \\ Lurdes Marlene Seide Froemming****
}

\begin{abstract}
Resumo
As pediatrias hospitalares passaram por mudanças estratégicas significativas ao longo do tempo, apostando no conforto, no bem-estar e no desenvolvimento do paciente infantil. As finalidades principais deste estudo foram identificar e analisar processos de mudanças e adaptação estratégica no atendimento pediátrico do Hospital de Caridade de Ijuí (HCI), localizado no município de Ijuí, RS. Foram utilizadas pesquisa bibliográfica e entrevistas. Foi possível identificar que as mudanças e a adaptação estratégica da pediatria do HCI eram conduzidas pelo ambiente externo e pela capacidade de o hospital e a pediatria identificarem oportunidades de desenvolvimento e expansão. Todos os processos foram indispensáveis para estabelecer diferenciais competitivos sustentáveis, promovendo o desenvolvimento da unidade pediátrica do HCI e do próprio hospital.
\end{abstract}

Palavras-chave: Ambiente hospitalar. Mudança e adaptação estratégica. Pediatria.

* Graduada em Comunicação Social - Publicidade e Propaganda, especialista em Marketing, mestre em Desenvolvimento Regional e doutoranda em Desenvolvimento Regional. Bolsista Prosuc/Capes na Unijuí. E-mail: jucapssa@gmail.com

** Pós-doutoramento em Administração na FGV. Professor nos cursos de mestrado e doutorado em Desenvolvimento Regional na Unijuí. E-mail: josausen@unijui.edu.br

*** Graduada em Administração pela Unijuí, mestre e doutora em Administração pela UFRGS. E-mail: lurdesf@unijui.edu.br 


\section{Introdução}

Nos últimos anos, as organizações têm passado por inúmeras transformações significativas, devido às mudanças mundiais produzidas pela globalização e pela consequente ascensão da tecnologia. O ambiente mercadológico está cada vez mais competitivo e adaptando-se continuamente; e as organizações garantem vantagens competitivas cada vez mais sustentáveis (WHITTINGTON, 2002).

Embora sob pressão do ambiente, as organizações têm condições de decidir quanto à escolha de suas estratégias, mesmo que muitas vezes limitadas pelo cenário. Isso recoloca o debate teórico sobre as pesquisas de estratégia orientadas pela abordagem funcionalista sem considerar o estrategista, os contextos macrossocial e organizacional (WHITTINGTON, 2002).

Nesse sentido, Bauer (1999) afirma que a imposição de adaptação do mercado às organizações proporcionou que atributos como a flexibilidade e a criatividade adquirissem mais importância que a mera eficiência, em detrimento de uma mentalidade mecanicista, para a valorização de uma mentalidade organicista. $\mathrm{Ou}$ seja, no contexto competitivo atual, ocorrem mudanças relevantes nos processos organizacionais, em que produtos e serviços são valorizados pela produtividade e pela inovação, por meio de processos contínuos de aprendizagem, conhecimento e aperfeiçoamento no interior das organizações.

Nesse contexto, a instituição hospitalar se caracteriza como uma complexa e completa organização social, uma vez que conta com múltiplas funções e objetivos nobres. Acompanhando a evolução e o desenvolvimento dos últimos anos da área da saúde, as pediatrias hospitalares também passaram por mudanças estratégicas significativas ao longo do tempo, apostando cada vez mais no conforto, no bem-estar e no desenvolvimento do paciente infantil, constituindo-se como um importante lócus de investigação para esta pesquisa.

O campo de pesquisa é o Hospital de Caridade de Ijuí (HCI), referência macrorregional em saúde, localizado no município de Ijuí, na Região Noroeste do estado do Rio Grande do Sul. Tem mais de 80 anos de atuação, ampla infraestrutura e oferta de serviço ao Sistema Único de Saúde (SUS) e a pacientes particulares e de outros convênios.

A pesquisa procurou identificar e analisar a história de evolução da pediatria do HCI, por meio da caracterização do processo de mudança e adaptação estratégica que envolveu o período de 1990 (ano em que a pediatria já era uma ala independente) a 2016 (ano de realização deste estudo). Buscou-se investigar a trajetória de atendimento pediátrico neste período de tempo, para, em seguida, descrever,

Teoria e Evidência Econômica - a. 24, n. 50, p. 207-229, jan./jun. 2018 
analisar e interpretar as informações obtidas, identificando eventos críticos e períodos-chave de mudança e de adaptação estratégica na pediatria da instituição hospitalar estudada, com relação ao seu conteúdo (qual a mudança), ao seu contexto (por que da mudança) e ao seu processo (como se deu a mudança), de acordo com o modelo de análise de mudança organizacional proposto por Pettigrew, Ferlie e Mckee (1992). Os períodos e seus principais eventos críticos foram relacionados às variáveis escolha estratégica e determinismo ambiental do modelo de tipologias de adaptação estratégica de Hrebiniak e Joyce (1985).

As transformações contextuais da saúde hospitalar a níveis local e regional e o entendimento da pediatria em relação a seu espaço, evidências físicas, profissionais de saúde integrantes e processos e ações desempenhados no atendimento voltado ao paciente infantil e respectivos acompanhantes e familiares foram referências para a análise do processo de mudança e adaptação estratégica no setor pediátrico da organização.

$\mathrm{O}$ artigo está divido em cinco etapas. A primeira parte procurou caracterizar o estudo. Posteriormente, realiza-se um apanhado acerca dos processos de mudança e de adaptação estratégica nas organizações, com foco para as organizações e pediatrias hospitalares, envolvendo o atendimento ao paciente infantil. Segue-se com a metodologia de pesquisa. Na sequência, apresentam-se a análise do processo de mudança e adaptação estratégica, com a construção dos principais eventos críticos e períodos estratégicos, e a análise teórica do estudo como um todo. Por fim, têm-se as considerações finais.

\section{Referencial teórico}

\section{Ambiente hospitalar e atendimento pediátrico}

Serviços organizacionais e institucionais dos mais diversos setores investem cada vez mais em estratégias competitivas. A sociedade pós-industrial é definida pela quantia de bens, como indicadores pelos serviços e amenidades (saúde, educação, recreação e artes), considerados desejáveis (RIFKIN, 2004).

Embora os profissionais de serviços enfrentem desafios na compreensão das necessidades e expectativas dos clientes no sentido de fornecer tangibilidade à oferta de serviços, quanto aos serviços hospitalares, é possível tangibilizá-los e diferenciá-los por meio da qualidade de ações humanas (atendimento funcionário-paciente) e ambientais (evidências físicas), uma vez que Zeithaml e Bitner (2003) 
classificam os hospitais como serviços interpessoais, baseados em uma complexidade elaborada do cenário de serviços.

O ambiente hospitalar, por si só, já cria no indivíduo sensações de angústia, de prisão, de medo (PINHEIRO; MATTOS, 2001). Considerando a inerente atmosfera vulnerável, tensa e angustiante dos hospitais, há a necessidade da promoção do conforto e dos bem-estares físico e emocional a pacientes e acompanhantes, por meio da humanização (MINAYO; MACHADO; PENA, 2011).

Se em serviços hospitalares, a humanização no atendimento e na atmosfera ambiental proporciona os bem-estares físico e emocional dos pacientes e de seus respectivos acompanhantes; nas pediatrias hospitalares, essas ações tornam-se indispensáveis para a criança, pois, na infância, os estímulos sensoriais e motores são desenvolvidos, e desenvolver as saúdes física e emocional infantis são indispensáveis para que possam criar condições de se autodesenvolver.

A busca pelo desenvolvimento humano e o foco no conforto e no bem-estar por meio da humanização - refletida na qualidade do atendimento funcionário-cliente, nos cenários de serviços e nas demais atividades e ações aplicadas neste contexto - são algumas das principais práticas estratégicas adotadas pelas instituições de saúde. Em um hospital, é fundamental a humanização, considerando a finalidade filantrópica de desenvolvimento da área da saúde, em conformidade com a classificação de Clark (1957), que considera os serviços de saúde no estágio quinário, ${ }^{1}$ primordial para o aperfeiçoamento e a ampliação das habilidades humanas.

Para tanto, é preciso dar condições para que o paciente sinta-se bem mediante a situação em que se encontra, sendo que a humanização deve partir de todos os integrantes da área hospitalar para todos os pacientes e familiares. Os funcionários na prestação do serviço são de grande importância, considerando que as empresas, intangíveis, se materializam pelas pessoas que nela exercem alguma função, que mudam procedimentos, criam, inovam, transformam planos em ações e modificam as próprias organizações (ZEITHAML; BITNER, 2003). Os funcionários são o serviço, são a organização aos olhos do cliente e são profissionais de mercado, influenciando nas percepções de qualidade dos serviços, por meio de um "trabalho emocional" no atendimento ao clientes.

O cuidado humano não pode ser prescrito, mas sentido, vivido e vivenciado; a questão do cuidado é uma ação integral, com significados e sentidos voltados para a compreensão de saúde como um direito de ser (WALDOW, 1998). É o tratar, o respeitar, o acolher, o atender o ser humano. A saúde deve ser encarada de uma forma complexa, afinal, o ser humano é um ser único, que compreende os aspectos biológicos, psicológicos e sociais (SALVAJOLY, 1999). O cuidar é uma atitude 
interativa que inclui o envolvimento e o relacionamento entre as partes, compreendendo acolhimento, escuta dos sujeitos, respeito pelo seu sofrimento e pelas suas histórias de vida (BOFF, 2001). Os sujeitos devem se sentir cuidados e acolhidos em suas demandas e necessidades.

Nesse contexto, a família também tem um papel fundamental, principalmente tratando-se de crianças, pelas quais é diretamente responsável. A atenção, o cuidado, o carinho e a ajuda devem estender-se, também, à família (VANZIN; NERY, 1997). Sendo a família um núcleo menor, que funciona como uma espécie de reduto emocional para o paciente enfrentar o processo de adoecimento, também proporciona segurança pela afetividade e pelo cuidado contínuos. As famílias precisam de cuidado e atenção especiais da equipe de saúde, para ajudar a solucionar os problemas e amenizar o sofrimento (VASCONCELLOS, 1998).

Em contextos pediátricos, a brincadeira terapêutica, a arteterapia e a musicoterapia configuram-se como estratégias lúdicas importantes na assistência e no desenvolvimento do paciente infantil (MARINELO; JARDIM, 2013). Outras importantes estratégias são as visitas e apresentações de palhaços que tornam o ambiente vivido pela criança hospitalizada mais leve e descontraído, melhorando a comunicação, a relação e a aceitação da hospitalização e dos tratamentos, constituindo-se num fator importante de promoção de bem-estar e de melhoria da qualidade de vida da criança hospitalizada (ESTEVES; ANTUNES; CAIRES, 2014).

Quanto aos cenários de serviços, projetos de arquitetura e de reestruturação ambiental na hotelaria hospitalar também são muito importantes para os pacientes infantis e seus familiares. A humanização dos espaços de saúde tem sido muito associada ao apelo à imagem e à ambiência de outras tipologias arquitetônicas, sugerindo atributos como sofisticação, conforto ou aconchego (CAVALCANTI; AZEVEDO; DUARTE, 2007). O cenário de serviços, por meio das evidências físicas, é um influenciador das respostas dos clientes, ao realizarem a experiência do serviço (ZEITHAML; BITNER, 2003). Nesse sentido, o uso de cores adequadas, o controle da iluminação, o contato com a natureza, a condição de orientabilidade e a personalização dos espaços fazem com que o ambiente hospitalar adquira um valor mais humano, aproximando-se da vida do paciente e afastando-se do caráter unicamente institucional (VASCONCELOS, 2004).

Portanto, no mundo dos negócios, em meio à acirrada competitividade e a demandas e necessidades cada vez maiores dos clientes e consumidores, as organizações estão constante e estrategicamente mudando, seja para sobressaírem-se ou para adequarem-se e adaptarem-se frente ao cenário a elas apresentado. E com as instituições de saúde hospitalares, não costuma ser diferente. 


\section{Escolha estratégica e determinismo ambiental}

Hrebiniak e Joyce (1985) desenvolveram um modelo de visão interativa do processo de adaptação estratégica nas organizações, em que consideram que a escolha e o determinismo são variáveis independentes, e sua interação ou interdependência é importante para explicar o comportamento organizacional.

A abordagem segue a lógica da teoria dos sistemas abertos das organizações, em que os sistemas e seus ambientes podem afetar os processos de troca e transformação, sugerindo independência e importância do efeito interativo, bem como equifinalidade, em que as mesmas consequências podem ser executadas de múltiplas maneiras, com diferentes resultados, diversos processos de transformação e vários métodos ou meios.

As interações influenciam o número e as formas de opções de estratégia organizacional, a ênfase que promove a decisão nos meios e fins, o comportamento político e os conflitos, e a busca de atividades da organização em seu ambiente.

Conforme o Quadro 1, a interação das variáveis resulta em quatro tipos. No quadrante I (Seleção natural), há alto grau de influência ambiental e baixa capacidade de escolha estratégica, devido à falta de recursos e à falta de força das organizações diante do ambiente. No quadrante II (Foco ou diferenciação), a escolha estratégica e o determinismo do meio são altos, caracterizando um contexto turbulento, com fatores externos gerando pressões sobre a tomada de decisões, causando restrições internas, mas apresentando também espaço para que a empresa faça suas próprias opções. No quadrante III (Escolha estratégica), há alto grau de escolha estratégica e baixo determinismo do meio, poucas restrições políticas, abundância de recursos internos e máximo poder de escolha, além de adaptação por design. No quadrante IV (Escolha indiferenciada), a escolha estratégica e o determinismo do meio são baixos, e as organizações não são capazes de criar dependência ou exercer influências, ou seja, tendem a ter pouca escolha estratégica, apesar da pouca restrição externa. 
Quadro 1 - Relação entre escolha estratégica e determinismo ambiental

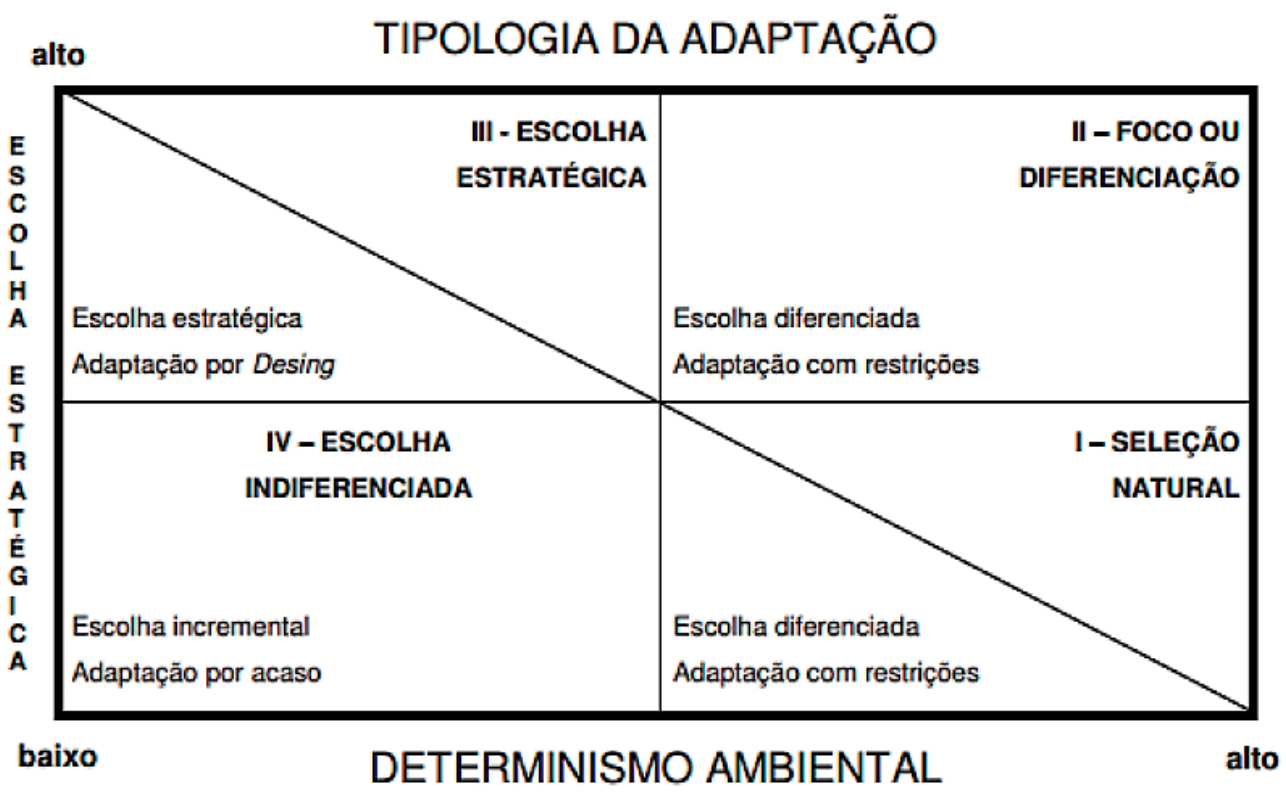

Fonte: Hrebiniak e Joyce (1985).

Dessa forma, a interdependência e a interação entre a escolha estratégica e o determinismo ambiental definem a adaptação, sendo que cada um dos itens isolados é insuficiente, e ambos são necessários para a explicação satisfatória da adaptação organizacional. A adaptação é, ainda, um processo dinâmico, resultado de força relativa e tipo de poder ou dependência entre organização e ambiente.

A adaptação como um processo dinâmico revela que, para qualquer organização, elementos ou variáveis relacionadas à escolha estratégica e ao determinismo ambiental existem simultaneamente. A tipologia sugere a complexidade e a interdependência das variáveis importantes e dos processos de decisão como uma função tanto de escolha quanto de determinismo.

\section{Metodologia}

O estudo classifica-se como de caso único e de abordagem qualitativa. A pesquisa qualitativa e o estudo de caso favorecem o engajamento do pesquisador com o cotidiano da administração, proporcionando uma compreensão profunda, ampla e integrada da realidade das organizações, constituindo-se numa rica fonte 
de informações para medidas de natureza prática e decisões políticas, trazendo contribuições para a pesquisa acadêmica e para a vida organizacional (GODOY, 2006). O estudo de caso foi realizado para a construção de modelos de análise de mudanças organizacionais. A construção do trabalho procedeu por estudo de caso descritivo, por meio de abordagem longitudinal/histórica, contextual e processual (PETTIGREW; FERLIE; MCKEE, 1992).

A pesquisa teve como objetivo identificar processos de mudança e adaptação estratégica na pediatria do HCI, nos últimos 26 anos. Buscou-se descrever toda a trajetória de atendimento pediátrico nesse período de tempo, para, em seguida, analisar e interpretar as informações obtidas, identificando eventos críticos e períodos-chave de mudança e adaptação estratégia pelo modelo seccional com perspectiva longitudinal (no qual a coleta de dados é feita em determinado momento, mas resgata dados e informações de períodos passados), a nível organizacional (considerando-se a instituição de saúde analisada), com foco nos espaços de atendimento pediátrico enquanto unidade de análise. Por fim, os períodos e seus principais eventos críticos foram relacionados às variáveis de escolha estratégica e determinismo ambiental do modelo de Hrebiniak e Joyce (1985).

Para a coleta e a análise dos dados, foram utilizadas pesquisa bibliográfica e entrevistas. A pesquisa bibliográfica incluiu livros sobre as temáticas abordadas e pesquisa no endereço eletrônico do HCI, ${ }^{2}$ acerca do histórico e da evolução da instituição. A principal fonte de informação foram as entrevistas em profundidade, pelo método direct research, proposto por Mintzberg (1997). De acordo com o autor, a direct research considera a pesquisa baseada em: descrição e indução; confiança no simples; medição de muitos elementos em termos de organizações, baseados em fatos históricos; e síntese desses elementos em grupos.

Foram realizadas entrevistas não estruturadas com três profissionais da área da saúde (duas enfermeiras e uma técnica de enfermagem), envolvidas direta e intensamente no atendimento pediátrico do HCI desde os tempos mais remotos até os mais recentes. Nessa parte do trabalho, utilizaram-se os modelos das categorias analíticas propostas por Pettigrew, Ferlie e Mckee (1992), para a análise do processo de mudança organizacional, que considera o conteúdo das mudanças (o que mudou), o contexto (por que mudou) e o processo (como mudou). O desafio da análise foi conectar as três categorias, para explicar o alcance diferencial de objetivos de mudança, identificando as várias causas da mudança por meio de uma visão eclética e processual que requereu habilidade de manuseio de questões. Tais categorias constam na descrição dos eventos de cada período e na análise e na interpretação das estratégias. 


\section{Mudança e adaptação estratégica na pediatria do HCI}

Mudanças deveriam ser vistas não só como consequência de um processo de solução de problemas, resultado da evidência técnica e da análise ou da direção gerencial para eficiência e efetividade, mas também como um produto de processos que reconhece lutas históricas e contínuas por poder e status como forças motoras (PETTIGREW; FERLIE; MCKEE, 1992). Afinal, uma visão do processo que combine elementos racionais, políticos e culturais tem poder real para explicar a continuidade e a mudança organizacional.

$\mathrm{O}$ atendimento pediátrico no HCI existe desde a construção do primeiro pavilhão, em 1940. Inicialmente, crianças e adultos eram internados no mesmo espaço, apesar de instalados em quartos separados. Durante a noite, não era permitido o acesso aos leitos de pais e acompanhantes dos pacientes infantis, e as crianças ficavam estritamente sob o cuidado e o acompanhamento de profissionais de saúde, especialmente de técnicos de enfermagem. Internações, tratamentos e procedimentos eram mais longos. Medicamentos eram mais restritos. Equipamentos eram mais rudimentares e manuais. Pais e acompanhantes eram mais desinformados e não eram orientados efetivamente quanto às patologias de suas crianças.

A análise do processo de mudança e adaptação estratégica da pediatria do HCI inicia em 1990 (ano em que a pediatria já era uma ala independente) e vai até 2016 (ano de realização deste estudo). Para explicar o processo de mudança e adaptação estratégica da pediatria do HCI no período de 1990 a 2016, foram identificados os eventos críticos (mudanças estratégicas de influência decisiva no processo de adaptação estratégica) e as características de maior relevância para a pediatria da organização. A partir desse levantamento, foram definidos três períodos estratégicos (conjunto de decisões que cria um padrão de comportamento característico) de mudança da pediatria da instituição estudada.

O Quadro 2 demonstra a síntese da análise dos períodos de mudança e a adaptação estratégica da pediatria do HCI pelas categorias analíticas de Pettigrew, Ferlie e Mckee (1992), que consideram o conteúdo das mudanças (o que mudou), o contexto (por que mudou) e o processo (como mudou). 
Quadro 2 - Síntese dos períodos de mudança e adaptação estratégica na pediatria do $\mathrm{HCl}$

\begin{tabular}{|c|c|c|c|}
\hline PERÍODOS & O QUÊ? & COMO? & POR QUÊ? \\
\hline $\begin{array}{c}\text { Período I } \\
\text { Consolidação } \\
\text { da unidade } \\
\text { pediátrica } \\
(1990-1999)\end{array}$ & $\begin{array}{c}\text { Unidade } \\
\text { pediátrica } \\
\text { específica para o } \\
\text { paciente infantil }\end{array}$ & $\begin{array}{l}\text { Local espaçoso; leitos cheios; internações } \\
\text { mais longas; vínculo bastante próximo en- } \\
\text { tre equipe e pacientes; humanização com } \\
\text { foco no cuidado e no tratamento; medica- } \\
\text { mentos, equipamentos, tratamentos e pro- } \\
\text { cedimentos primitivos. }\end{array}$ & $\begin{array}{l}\text { Foco nas atividades e ne- } \\
\text { cessidades do paciente in- } \\
\text { fantil }\end{array}$ \\
\hline Período II & $\begin{array}{l}\text { Mudança da } \\
\text { pediatria para o } \\
\text { quarto piso }\end{array}$ & $\begin{array}{l}\text { Estrutura mais ampla, aconchegante e } \\
\text { confortável; leitos cheios; internações rá- } \\
\text { pidas; vínculo próximo entre equipe e pa- } \\
\text { cientes; medicamentos, equipamentos, } \\
\text { tratamentos e procedimentos mais avan- } \\
\text { çados; profissionais de outras áreas da } \\
\text { saúde; humanização intensa, com foco em } \\
\text { eventos, atividades e na infraestrutura. }\end{array}$ & $\begin{array}{l}\text { Avanços em administração, } \\
\text { saúde e tecnologia; inaugu- } \\
\text { ração das UTIs neonatal e } \\
\text { pediátrica em 2000; abertu- } \\
\text { ra do Centro de Alta Com- } \\
\text { plexidade em Oncologia em } \\
\text { 2003; surgimento do Grupo } \\
\text { de Trabalho de Humaniza- } \\
\text { ção em } 2003 \text {. }\end{array}$ \\
\hline $\begin{array}{c}\text { Período III } \\
\text { Mudança do } \\
\text { foco estratégico } \\
(2015-2016)\end{array}$ & $\begin{array}{l}\text { Mudança da } \\
\text { pediatria para o } \\
\text { terceiro piso }\end{array}$ & $\begin{array}{l}\text { Estrutura de atendimento misto; espaço } \\
\text { menor, porém mais aconchegante; pouca } \\
\text { ocupação de leitos; internações mais cur- } \\
\text { tas; avanço significativo em medicamen- } \\
\text { tos, equipamentos, tratamentos e proce- } \\
\text { dimentos; departamentalização de setores } \\
\text { e funções; profissionais de diversas áreas } \\
\text { da saúde; vínculo técnico entre equipe e } \\
\text { pacientes; humanização menos frequente. }\end{array}$ & $\begin{array}{l}\text { Diminuição significativa de } \\
\text { internações devido à perda } \\
\text { de credenciamento do HCl } \\
\text { para atendimento de pa- } \\
\text { cientes infantis com câncer } \\
\text { em 2008; fortalecimento } \\
\text { dos programas de saúde } \\
\text { preventiva; abertura do } \\
\text { Hospital Unimed em } 2009 \text {; } \\
\text { extinção da UTI pediátrica } \\
\text { em 2015; diminuição de } \\
\text { plantões pediátricos, avan- } \\
\text { ços na saúde e tecnologia. }\end{array}$ \\
\hline
\end{tabular}

Fonte: elaboração dos autores.

A seguir, são apresentados cada período estratégico, com seus eventos críticos e características marcantes, bem como a análise de cada período de acordo com a visão interativa das variáveis de escolha estratégica e determinismo ambiental, no processo de adaptação das organizações, conforme proposto por Hrebiniak e Joyce (1985). 


\section{Período estratégico I - Consolidação da unidade pediátrica (1990-1999)}

Entre os serviços administrativos do HCI, a pediatria, apesar das muitas demandas e melhorias a serem feitas, teve sua consolidação neste período. Já existia um local específico (um andar inteiro) para a ala pediátrica. Com um espaço específico para as crianças, aumentou a possibilidade de focar mais nas atividades e necessidades destinadas a elas. A unidade pediátrica era constituída por 28 leitos (lotados, mas com quartos menores) e uma sala de emergência e atendida por duas enfermeiras. Não existiam Unidades de Terapia Intensiva (UTIs) neonatal nem pediátrica. Casos graves eram encaminhados para Porto Alegre ou Santa Maria. Quando não havia como ou para onde ir, os pacientes eram encaminhados para a UTI adulta. Crianças com câncer eram internadas e tratadas em leitos isolados.

$\mathrm{O}$ atendimento pediátrico acontecia em três turnos. Atuava apenas uma enfermeira-chefe na noite para o hospital todo. Além de enfermeiros, a equipe profissional restringia-se aos técnicos de enfermagem, médicos pediatras, nutricionista e fisioterapeuta (gerais para o hospital), caso necessário. Existia um número considerável de médicos pediatras. Os técnicos de enfermagem, muitas vezes, assumiam responsabilidades destinadas atualmente aos médicos e enfermeiros, pois não havia uma hierarquia definida de tarefas. Com exceção de casos de pneumonia severa, dificilmente havia criança em fisioterapia. O nutricionista atuava mais que o fisioterapeuta. As refeições eram elaboradas manualmente na cozinha, e não existia dieta enteral (ingestão controlada de nutrientes). A relação entre os profissionais era próxima, existia um envolvimento maior entre eles e deles com os pacientes.

Alguns quartos tinham televisão. Não havia ar condicionado instalado. As pessoas se acomodavam em cadeiras, e, muitas vezes, faltavam cadeiras nos leitos. Os medicamentos eram mais primitivos (penicilina, oxacilina, sulfenicol), assim como os equipamentos (nebulizadores portáteis, não havia bombas de infusão para soro), os tratamentos (crianças em processo quimioterápico eram controladas a olho nu) e os procedimentos (impressos, manuais).

Tratamentos e internações eram mais longos. Pacientes consultavam muito, e a maioria, atendida em postos de saúde e prontos-socorros, era internada. Profissionais da saúde (incluindo os agentes de saúde) não tinham a conduta de otimização e prevenção da saúde preventiva. Consequentemente, faltava aos pais maior orientação. Em contrapartida, pais eram autorizados a acompanhar suas crianças também no turno da noite. 
Não existia decoração da pediatria, nem eram realizadas atividades lúdicas e de entretenimento para as crianças. As ações de humanização ficavam restritas ao tratamento e ao cuidado com os pacientes e seus pertences. O voluntariado era intenso nesse sentido. Alguns voluntários costuravam fraldas e pijamas para as crianças.

Portanto, os contextos (interno e externo) deste período caracterizaram a pediatria do HCI no quadrante I (Seleção natural), de Hrebiniak e Joyce (1985), em que há alto grau de influência ambiental e baixa capacidade de escolha estratégica, devido à falta de recursos e à falta de força organizacional perante 0 ambiente.

A consolidação de uma estrutura específica para atendimento e internação infantil foi resultado de uma demanda da própria comunidade e do hospital enquanto instituição de saúde, para que se pudesse focar mais nas atividades e necessidades destinadas às crianças. $\mathrm{E}$, apesar da consolidação da unidade pediátrica, existiam limitações de medicamentos, equipamentos, tratamentos e procedimentos em conformidade com os avanços mais lentos nas áreas da saúde e da tecnologia da época.

Nesse quadro, o período de consolidação da unidade pediátrica foi consequência de um arranjo institucional criado sob a pressão do contexto. Não foi uma unidade criada de forma planejada, mas fruto de contingências e pressões, principalmente do contexto externo (da comunidade), característica do quadrante I do modelo de Hrebiniak e Joyce (1985).

\section{Período estratégico II - Desenvolvimento e expansão (2000-2014)}

Avanços administrativos nas áreas de saúde e tecnologia assim como a inauguração das UTIs neonatal e pediátrica em 2000, a abertura do Centro de Alta Complexidade em Oncologia (Cacon) em 2003 e o surgimento do Grupo de Trabalho de Humanização (GTH) também em 2003 permitiram uma evolução considerável da pediatria no período.

Em 2000, a pediatria do HCI mudou-se do térreo para todo o quarto piso. A estrutura tornou-se mais ampla, aconchegante e confortável para pacientes e acompanhantes (instalação de televisão e ar condicionado nos quartos privativos, poltronas em todos os leitos); aumentou o número de técnicos de enfermagem; medicações e tratamentos avançaram; foram otimizados os procedimentos (via sistema) e adquiridos equipamentos modernos e de alta qualidade (nebulizadores canalizados nas paredes, bombas de infusão para soro). 
$\mathrm{O}$ atendimento era mantido nos três turnos, com enfermeiras responsáveis nos turnos da manhã e da tarde e com outra (geral para o hospital) no período da noite. Internações infantis ficaram mais curtas (média de 7 a 10 dias). Com a otimização dos procedimentos e o avanço das medicações e dos tratamentos, as melhoras eram mais efetivas e, portanto, mais rápidas. Pais e familiares próximos continuavam acompanhando o paciente infantil no período noturno.

Havia uma ala SUS e uma ala de convênios, totalizando 32 leitos, sempre cheios, em que a ocupação era de $90 \%$ dos leitos. Na ala SUS, havia três enfermarias (cada uma com seis leitos), divididas por patologias (infecções respiratórias, gastroenterites e pós-cirurgia). Nas enfermarias, eram muitas as internações por infecção respiratória e gastroenterite. $\mathrm{Na}$ ala de convênios, grande parte das internações era por infecção respiratória e cirurgias.

A pediatria era referência em oncologia pediátrica. Eram internadas muitas crianças com câncer, atendidas por um especialista em hematologia e oncologia. Internavam para fazer quimioterapia, por complicações da própria quimioterapia ou por conta da evolução da doença. Devido à fragilidade do paciente e às internações intensas e frequentes, existia um vínculo muito próximo da equipe com essas crianças e suas famílias. Para essas crianças, existiam leitos individuais de isolamento.

Com o surgimento do GTH em 2003, as ações de humanização ficaram mais intensas. Entretenimento com palhaços e apresentações teatrais e musicais (participação do coral do HCI) eram algumas das atividades proporcionadas aos pacientes infantis, especialmente nas datas comemorativas (dia da criança, Páscoa, Natal), tanto no auditório do hospital quanto na unidade pediátrica. A decoração lúdica remetendo ao universo infantil, com muitos desenhos e cores, era destaque na pediatria.

Outro diferencial foi a sala da brinquedoteca, inaugurada após a mudança. Era um espaço amplo, que permitia à criança hospitalizada manter sua principal fonte de alegria, o brincar, com o intuito de humanizar o ambiente hospitalar, fazendo com que se restabelecesse mais rapidamente, amenizando o período de internação, tanto para a criança como para os familiares que a acompanhavam. Nesse espaço, eram desenvolvidas ações de recreação e oferecidas atividades lúdicas, planejadas e orientadas por profissional de pedagogia que permanecia nos turnos da manhã e da tarde, por 40 horas semanais.

Havia diversas opções para as crianças interagirem e brincarem, incluindo banquinhos, mesas, brinquedos diversos, revistas para desenhar e pintar, livros de história, etc. A participação de voluntários ajudava a alegrar ainda mais o ambiente, com brincadeiras e fantasias. A brinquedoteca recebia doação de brinquedos, 
livros, vídeos e jogos pedagógicos para as crianças. As crianças faziam cartões para a equipe e pintavam painéis que ficavam expostos em um mural definido. Todos os anos comemorava-se o aniversário da brinquedoteca, um grande evento com diversas atividades, que reunia pacientes, familiares, médicos pediatras e demais profissionais da pediatria.

Nesse período, a pediatria encontrava-se no quadrante III (Escolha estratégica), de Hrebiniak e Joyce (1985), com alto grau de escolha estratégica e baixo determinismo do meio, poucas restrições, abundância de recursos e máximo poder de escolha e adaptação pelo design.

Avanços nas áreas administrativa, da saúde e da tecnologia que culminaram na inauguração das UTIs neonatal e pediátrica em 2000, na abertura do Cacon em 2003 e no surgimento do GTH também em 2003 influenciaram positivamente $o$ desenvolvimento e a expansão da pediatria, porém sem pressões externas.

Ao mesmo tempo, conforme ia ascendendo, a pediatria foi se aperfeiçoando, se renovando, se fortalecendo, se tornando cada vez mais ativa e autossustentável em função de: mudança para uma estrutura mais ampla, aconchegante e confortável; medicamentos, equipamentos, tratamentos e procedimentos mais avançados; internações mais curtas; atuação de profissionais de outras áreas da saúde; e humanização intensa com foco em eventos, atividades e infraestrutura.

Portanto, este momento caracteriza-se como um período em que a capacidade de escolha estratégica foi mais alta do que as pressões do meio, como aconteceu no período anterior. Neste período, o planejamento e a capacidade de escolha estratégica, com a oferta de novos serviços e instalações, determinaram uma fase de expansão e qualificação da unidade pediátrica.

\section{Período estratégico III - Mudança do foco estratégico (2015-2016)}

Este período foi marcado pela diminuição significativa das internações na pediatria, ocasionada por diversos eventos, como a perda de credenciamento do HCI para atendimento de pacientes infantis com câncer em 2008, ocasionada por uma nova norma da Vigilância Sanitária, que exige médico especialista em oncologia pediátrica, não disponível no hospital para o atendimento dessas crianças. Desde então, os pacientes infantis são encaminhados para Santa Maria e Porto Alegre, centros de referência em oncologia pediátrica.

Outra causa importante para a redução das internações foi o fortalecimento dos programas de saúde preventiva, por meio de atuação intensa: da Estratégia de 
Saúde da Família, dos postos de saúde, dos médicos integrados às unidades básicas de saúde, dos agentes de saúde nas casas dos pacientes, da ampliação e do aperfeiçoamento dos programas de vacinação para as doenças imunopreveníveis e, consequentemente, da maior orientação dos profissionais aos pais e acompanhantes quanto ao encaminhamento para as internações (maior intermediação dos postos nos atendimentos).

Outros eventos contribuintes foram: abertura do Hospital Unimed em 2009, extinção da UTI pediátrica em 2015 e migração de médicos pediatras para as demais UTIs, diminuindo a frequência de plantões pediátricos. Além disso, com os avanços tecnológicos contínuos na área da saúde, foram otimizados os procedimentos, as medicações e os tratamentos avançaram mais, e, portanto, as internações estão ainda mais curtas do que no período anterior, com uma média de três a cinco dias, sendo que as mais longas não ultrapassam 15 dias.

Por não haver mais internações de crianças em número significativo, não houve mais sentido ter uma estrutura ampla de internação. Dessa forma, enquanto processo decisório estratégico para viabilizar os recursos financeiros, a pediatria mudou, no início de 2015, do quarto piso (onde está a maternidade) para o terceiro piso (onde ficava a cardiologia). A pediatria, mais enxuta, conta com 13 leitos e atende crianças de 29 dias a 12 anos de idade. Atualmente não tem nem 50\% da ocupação de crianças. No dia de aplicação da entrevista, havia apenas duas crianças internadas (uma no limite de idade - 12 anos - e outra de três anos). O máximo de crianças atendidas desde a sua nova estrutura foram oito crianças, considerando o período de inverno.

São três quartos de enfermaria (três leitos cada), dois quartos privativos e um semiprivativo. Além da unidade de internação (quartos de internação e emergência), a pediatria tem posto de saúde e cozinha. As enfermarias continuam divididas por patologias (gastroenterite, pneumonia, cirurgia e traumatologia). Inverno e verão são as épocas de maior internação. No verão, as maiores internações são por gastroenterites. No inverno, a principal causa são as infecções respiratórias. Internações na traumatologia e na cirurgia variam. Com a extinção da UTI pediátrica devido à redução de pacientes infantis, crianças em risco utilizam a estrutura da UTI adulta e, depois de receberam alta, são encaminhadas para a pediatria.

A pediatria continua atendendo nos três turnos. Existem maiores segmentação e departamentalização das funções e dos setores, contando, inclusive, com supervisoras para as áreas abertas e fechadas desde 2011. Cada turno (manhã, tarde e noite) conta com uma enfermeira coordenadora geral da pediatria. A pediatria tem, ainda: enfermeiros plantonistas noturnos; enfermeiros supervisores 
nos fins de semana; 11 técnicos de enfermagem (três de manhã, três de tarde e cinco de noite); aproximadamente oito médicos pediatras credenciados (três plantonistas do hospital na pediatria, dois nos fins de semana); fisioterapeuta (principalmente para crianças pós-cirúrgicas ou com infecção respiratória); nutricionista (para crianças que saem da UTI e precisam de acompanhamento e adaptação de dieta nutricional); profissional de serviço social (especialmente para crianças de famílias com pouco ou nenhum recurso financeiro e acompanhadas pelo conselho tutelar); fonoaudiólogo (para crianças que saem da UTI neonatal); e psicólogo (que atua pelo Cacon). Profissionais para a copa e higienização complementam o quadro funcional.

Fisioterapeuta, nutricionista, fonoaudiólogo e psicólogo não são profissionais específicos da pediatria. Porém, com o maior acesso à informação e o aperfeiçoamento dos serviços de saúde, aumentaram a procura e a necessidade por profissionais de diversas áreas. Crianças em condições especiais requerem o acompanhamento de profissionais aptos a atender suas demandas. Essas crianças têm acompanhamento direcionado com fisioterapeuta e psicólogo. Quanto à alimentação, o nutricionista avalia e elabora a dieta enteral. Dietas dependem muito da patologia da criança. Dietas especiais são elaboradas para crianças diabéticas ou com intolerâncias à lactose ou ao glúten.

Com a categorização e a departamentalização de funções e setores, ocorreu uma otimização do fluxograma da pediatria. Se, por um lado, diminuiu o número de técnicos de enfermagem, devido à redução das internações infantis, por outro, os técnicos assumem uma responsabilidade maior na intermediação da relação entre enfermeiro, médico e paciente. Se o paciente não está bem, o técnico de enfermagem comunica o enfermeiro, e este comunica o médico. Já os enfermeiros assumem a gestão e a orientação de suas respectivas equipes.

Pais e familiares continuam acompanhando o paciente internado, independentemente de turno. Devido ao acesso facilitado à informação, estão mais atualizados, descrevem boa parte das informações necessárias para a equipe de atendimento, fazem perguntas mais pontuais, e, muitas vezes, o profissional da área da saúde acaba apenas complementando e especificando mais essas informações.

Apesar de ser um espaço capacitado para atender crianças, a unidade pediátrica voltou a ser mista. Por faltar leitos SUS e sobrar leitos na pediatria, são internados também pacientes adultos nessa ala. Crianças e adultos são internados em quartos separados. Apesar dos poucos pacientes infantis, o hospital manteve a pediatria, considerando a necessidade de atendimento diferenciado. A criança é delicada e minuciosa, e isso reflete inclusive na aplicação de medicamentos 
(superfracionados e rediluídos) e nas habilidades técnicas (puncionar veia). Como forma de humanizar e qualificar o cuidado, foi mantida a disciplina pediátrica, com profissionais de referência e experientes em pediatria em todos os turnos, muitos deles coma experiência de atuar na antiga pediatria, e profissionais habilitados para atender tanto criança quanto adulto.

Os quartos têm televisão. Quartos conveniados e privativos têm aparelho de DVD, televisão a cabo e ar condicionado. Todos os leitos continuam acompanhados por poltronas. Apesar de não manter mais uma brinquedoteca, a pediatria conta com um espaço para crianças no final do corredor. Assim como a antiga brinquedoteca, esse espaço tem banquinhos, mesa, brinquedos, revistas para desenhar e pintar e livros de história. Crianças podem brincar tanto nesse espaço quanto levar os brinquedos e materiais para seu leito. Não há atuação de profissional de pedagogia para atender e orientar as crianças e interagir com elas. Os próprios pais, acompanhantes e alguns voluntários (não frequentemente) desempenham este papel. Para humanizar ainda mais o cuidado, além de os jalecos serem diferenciados, o ambiente conta com decoração lúdica, porém sutil, com destaque para personagens de desenho animado nas portas e em alguns locais da pediatria.

Eventos e ações de humanização acontecem de dia e com menos frequência. Muitas ações têm o suporte do GTH - com reuniões mais esporádicas -, de organizadores de eventos culturais e de voluntários de grupos teatrais e musicais (por meio de igrejas parceiras da instituição, para suprir as atividades do extinto coral do HCI). As atividades incluem entrega de presentes para as crianças, apresentações musicais, de canto e teatrais, entretenimento com palhaços, visitas, rezas e mensagens positivas. Muitas das atividades são promovidas em datas comemorativas (dia da criança, Natal e Páscoa) e, muitas vezes, são direcionadas não apenas para as crianças, mas para os demais pacientes internados. Doações de roupas, calçados e fraldas pelos próprios funcionários e por voluntários para as crianças carentes internadas também fazem parte das ações.

Apesar do espaço reduzido na pediatria e da diminuição das internações, os profissionais que trabalham nessa ala ressaltam que se continua tendo um espaço e ações voltados para a criança, pois sempre há crianças internadas com demandas a serem atendidas, e que futuramente talvez consigam reestruturar e direcionar melhor a unidade pediátrica, promovendo um ambiente mais acolhedor para a criança.

Este último período classifica a pediatria do HCI no quadrante II (Foco ou diferenciação), de Hrebiniak e Joyce (1985), em que a escolha estratégica e o determinismo do meio são altos, caracterizando um contexto turbulento, com fatores 
externos gerando pressões sobre a tomada de decisões, mas havendo espaço para que a organização faça suas próprias opções.

A perda de credenciamento do HCI para atendimento de pacientes infantis com câncer em 2008, o fortalecimento dos programas de saúde preventiva, a abertura do Hospital Unimed em 2009, a extinção da UTI pediátrica em 2015, a diminuição de plantões pediátricos e os avanços na saúde e na tecnologia foram fatores determinantes para a diminuição significativa de pacientes infantis internados na pediatria.

Para se adaptar às demandas do mercado e enquanto processo decisório estratégico de viabilização dos recursos financeiros, a pediatria teve que se reestruturar. Mudou-se para uma estrutura menor, de atendimento misto (criança e adulto); o vínculo entre equipe e pacientes tornou-se mais técnico; e as atividades e os espaços de humanização ficaram mais restritos. Porém, a ala pediátrica está mais aconchegante e moderna, além de contar com o avanço significativo de medicamentos, equipamentos, tratamentos e procedimentos, com a departamentalização maior de setores e funções e com atuação e contribuição de profissionais de diversas áreas da saúde.

Se o segundo período estratégico foi marcado por um processo de desenvolvimento e expansão, este período é caracterizado por um processo de ajuste e adequação, fruto das mudanças que aconteceram na área da saúde e exigiram da instituição medidas de contenção de gastos e, sobretudo, aproveitamento de espaços e profissionais. Portanto, o terceiro período é marcado por um conjunto de ações estratégicas que misturam pressões externas e a capacidade de fazer escolhas da coordenação da unidade pediátrica, de modo a classificá-lo no quadrante II da tipologia de adaptação estratégica do modelo de Hrebiniak e Joyce (1985).

\section{Considerações finais}

Esta pesquisa propôs-se a compreender, pela interpretação de profissionais da área da saúde que atuam na pediatria do HCI, o processo de adaptação estratégia da pediatria no período de 1990 a 2016. Buscou esclarecer quais foram as mudanças estratégicas, como essas mudanças se desenvolveram e que fatores internos e externos as influenciaram, além de descrever a percepção dos ambientes interno e externo dos profissionais entrevistados. As abordagens teóricas adotadas para esta pesquisa também deram subsídios para relacionar eventos externos e internos de influência e relevância e contextualizar o modo como a pediatria do HCI vem atuando. 
Por meio da análise, foi possível identificar que as mudanças e a adaptação estratégica da pediatria do HCI foram conduzidas, em alguns momentos, pelo meio e pelo ambiente externos, em outros, pelas capacidades do hospital e da pediatria de identificar oportunidades de desenvolvimento e expansão. Os períodos I e III destacaram o meio como determinante dos processos de mudança e adaptação estratégica no HCI. Nesses casos, houve processos de planejamento em termos de concepção do serviço e de adequação desse serviço às exigências e contingências do mercado. Já o período II foi marcado por escolhas estratégicas significativas, colocadas em prática pela própria pediatria, em ascensão na época.

Tais análises vão ao encontro da visão interativa do processo de adaptação nas organizações, de Hrebiniak e Joyce (1985), que se refere às capacidades de as organizações adaptarem-se ao ambiente, constituído de forças concomitantes de determinismo e voluntarismo.

Nesse sentido, em meio a momentos de limitações e conflitos norteados pelo determinismo ambiental, o HCI e sua respectiva unidade pediátrica, sempre que possível, procuraram estar voltados a estratégias e ações voluntaristas, com o intuito de se manter constantemente diferenciados e fortalecidos perante a comunidade.

Contudo, todos os períodos, eventos e acontecimentos foram marcantes e indispensáveis para estabelecer diferenciais competitivos sustentáveis, promovendo o crescimento, o desenvolvimento e a maturidade não apenas da pediatria, como também da instituição hospitalar como um todo, contribuindo para gerar valor e reconhecimento na comunidade e nas áreas hospitalar e da saúde.

Somam-se a isso o reconhecimento da instituição acerca da importância da humanização dos serviços pediátricos para o desenvolvimento infantil e o reconhecimento da necessidade de melhorias e transformações contínuas no contexto pediátrico, seja em serviços, atendimento e interação da equipe com os pacientes infantis e seus familiares, seja nos processos envolvendo o contexto pediátrico-hospitalar.

O estudo abordou, também, aspectos referentes ao ambiente hospitalar, ao atendimento pediátrico e aos processos de mudança e adaptação estratégica das organizações e, especificamente, da pediatria do HCI, para identificar oportunidades e estratégias, bem como ameaças.

O estudo oferece, ainda, contribuições gerenciais, pois a compreensão dos episódios adaptativos e de mudança permitiu apresentar a teoria e a prática, possibilitando a reflexão e a avaliação sobre o comportamento estratégico. Dessa forma, vem a ser relevante para profissionais da área da saúde, para administradores de pediatrias e de hospitais e para gestão e desenvolvimento dos hospitais, a níveis local, regional e nacional. 
Para continuidade deste tipo de pesquisa, recomenda-se um estudo de multicaso, de modo a comparar os processos de criação e adaptação deste tipo de serviço (unidade pediátrica), tão importante para as comunidades, principalmente entre os hospitais comunitários e filantrópicos, que exercem um papel importante no atendimento à saúde no interior do estado, ou seja, em regiões distantes dos grandes centros. 


\title{
The consolidation and development process pediatric unit of a philanthropic hospital under the strategic adaptation types
}

\begin{abstract}
Hospital pediatricians underwent significant strategic changes over time, focusing on the comfort, well-being and development of the child patient. The main purpose of this study was to identify and analyze processes of change and strategic adaptation in the pediatric care of the Hospital of Charity of Ijuí (HCI), located in the city of Ijuí, RS. Bibliographic research and interviews were used. It was possible to identify that the changes and strategic adaptation of HCI pediatrics were driven by the external environment and by the capacity of the hospital and pediatrics to identify opportunities for development and expansion. All processes were indispensable to establish sustainable competitive differentials, promoting the development of the pediatric HCI unit and the hospital itself.
\end{abstract}

Keywords: Hospital environment. Strategic change and adaptation. Pediatrics.

\section{El procedimiento de consolidación y desarrollo de la unidad pediátrica de un hospital filantrópico bajo la mirada de las tipologías de adaptación estratégica}

\section{Resumen}

Hospitalarias salas de pediatría han experimentado cambios significativos estratégicas con el tiempo, se centra en el confort, el bienestar y el desarrollo del niño paciente. El objetivo principal de este estudio fue identificar y analizar los procesos de cambio y ajuste estratégico en la atención pediátrica del Hospital de la Caridad de Ijuí (HCI), que se encuentra en la ciudad de Ijuí, RS. Se utilizaron la investigación bibliográfica y entrevistas. Fue posible identificar los cambios y el ajuste estratégico de HCI Pediatría se llevaron a cabo por el ambiente externo y la capacidad y pediatría del hospital a identificar oportunidades para el desarrollo y expansión. Todos los archivos son indispensables para establecer ventajas competitivas sostenibles, promoviendo el desarrollo de la unidad de pediatría del $\mathrm{HCl}$ y del propio hospital.

Palabras clave: Medio hospitalario. Cambio estratégico y adaptación. Pediatría. 


\section{Notas}

1 Setor econômico que inclui serviços sem objetivo de lucro, como a saúde, a educação, a cultura, a investigação (não remunerada), a polícia, os bombeiros e as organizações não governamentais.

2 Disponível em: <http://www.hci.org.br>. Acesso em: $08 \mathrm{dez} .2016$.

\section{Referências}

BAUER, R. Gestão da mudança: caos e complexidade nas organizações. São Paulo: Atlas, 1999.

BOFF, Leonardo. Saber cuidar: ética do humano, compaixão pela terra. Petrópolis: Vozes, 2001.

CAVALCANTI, Patrícia Biasi; AZEVEDO, Giselle Arteiro Nielsen; DUARTE, Cristiane Rose. Humanização, imagem e caráter dos espaços de saúde. Cadernos Proarq, Rio de Janeiro, v. 11, p. 7-10, 2007.

CLARK, Colin. The conditions of economic progress. 3. ed. Londres: The Macmillan, 1957.

ESTEVES, Carla Hiolanda; ANTUNES, Conceição; CAIRES, Susana. Humanização em contexto pediátrico: o papel dos palhaços na melhoria do ambiente vivido pela criança hospitalizada. Interface, Botucatu, v. 18, n. 51, p. 697-708, 2014.

GODOY, A. S. Estudo de caso qualitativo. In: GODOI, C. K.; BANDEIRA-DE-MELLO; SILVA, A. B. (Org.). Pesquisa qualitativa em estudos organizacionais: paradigmas, estratégias e métodos. São Paulo: Saraiva, 2006. p. 115-146.

HREBINIAK, L. G.; JOYCE, W. F. Organizational adaptation: strategic choice and environmental determinism. Administrative Science Quarterly, New York, v. 30, p. 336-349, 1985.

MARINELO, Gisele dos Santos; JARDIM, Dulcilene Pereira. Estratégias lúdicas na assistência ao paciente pediátrico: aplicabilidade ao ambiente cirúrgico. $S O B E C C$, São Paulo, v. 18, n. 2, p. 57-66, abr./jun. 2013.

MINAYO, Carlos; MACHADO, Jorge Mesquita Huet; PENA, Paulo Gilvane Lopes. Saúde do trabalhador na sociedade brasileira contemporânea. Rio de Janeiro: Fiocruz, 2011.

MINTZBERG, H. An emerging strategy of direct research. Administrative Science Quarterly, New York, v. 24, n. 9, p. 582-589, 1997.

PETTIGREW, A.; FERLIE, E.; MCKEE, L. Understanding the process of organizational change. In:__. Shaping strategic change. London: Sage Publications, 1992. p. 609-611.

PINHEIRO, Roseni; MATTOS, Rubens. Cuidado: a fronteira da integralidade. Rio de Janeiro: CEPESC/UERJ, 2001.

RIFKIN, Jeremy. A era do acesso. Trad. Maria Lucia G. L. Rosa. São Paulo: Pearson, 2004.

SALVAJOLY, João Victor. O cuidar em oncologia. Rio de Janeiro: Medsi, 1999.

VANZIN, Arlete Spencer; NERY, Maria Elena da Silva. O curar e o cuidar. São Paulo: Cortez, 1997.

VASCONCELLOS, Ana Maria (Org.). A prática do serviço social. São Paulo: Cortez, 1998. 
VASCONCELOS, Renata Thaís Bomm. Humanização de ambientes hospitalares: características arquitetônicas responsáveis pela integração interior/exterior. 2004. Dissertação (Mestrado em Arquitetura e Urbanismo)-Programa de Pós-Graduação em Arquitetura e Urbanismo, Universidade Federal de Santa Catarina, Florianópolis, 2004.

WALDOW, Vera Regina. Cuidado humano: o resgate necessário. Porto Alegre: Sagra Luzzatto, 1998.

WHITTINGTON, R. The work os strategizing and organizing: for a practice perspective. IEEE Acoustics, Speech, and Signal Processing Newsletter, v. I, n. I, p. 119-127, 2002.

ZEITHAML, Valarie H.; BITNER, Mary Jo. Marketing de serviços: a empresa com foco no Cliente. Porto Alegre: Bookman, 2003. 